\title{
Acute Patella Tendon Rupture: A Case Report
}

\author{
Ilahiane M*, Abdulrazak S, Hassani I, Marzouki A and Boutayeb F \\ Department of orthopaedic surgery, Hassan II hospital, Fès, Morocco
}

Submission: October 29, 2018; Published: November 26, 2018

*Corresponding author: Ilahiane Mohamed, Department of orthopaedic surgery, Hassan II hospital, Fès, Morocco

\begin{abstract}
Acute patella tendon ruptures are relatively infrequent compared to quadriceps tendon ruptures. We hereby present the case of a 23 -yearold male who suffered a sports injury causing a rupture of this patellar tendon. Surgical repair and the early rehabilitation allow for complete recovery of knee function and early return to pre-injury activity level in most cases.

Keywords: Acute patella; Tendon rupture; Transosseous suture; Wire reinforcement; Early motion
\end{abstract}

\section{Introduction}

Acute patellar tendon ruptures are less frequent than quadriceps tendon ruptures. Nearly $80 \%$ of cases affect young adult males less than 40 years old [1]. Rupture occurs mostly at the inferior border of the patella, sometimes closer to its insertion on the tibial tuberosity. Similar to the quadriceps tendon, full body rupture is rare and often associated with systemic disease, metabolic disorders, anabolic steroid abuse, chronic local steroid

Case Report injections and long fluoroquinolone use responsible for the onset of gradual tendon degenerative process. In young athletes, patellar tendinopathy (jumper knee) or sequelae of other enthesopathies such as Osgood-Schlatter disease are also considered major risk factors [2]. We intend to highlight the operative management and rehabilitation protocol of acute patella tendon rupture in young athletes through a rare case report and review of relevant literature.

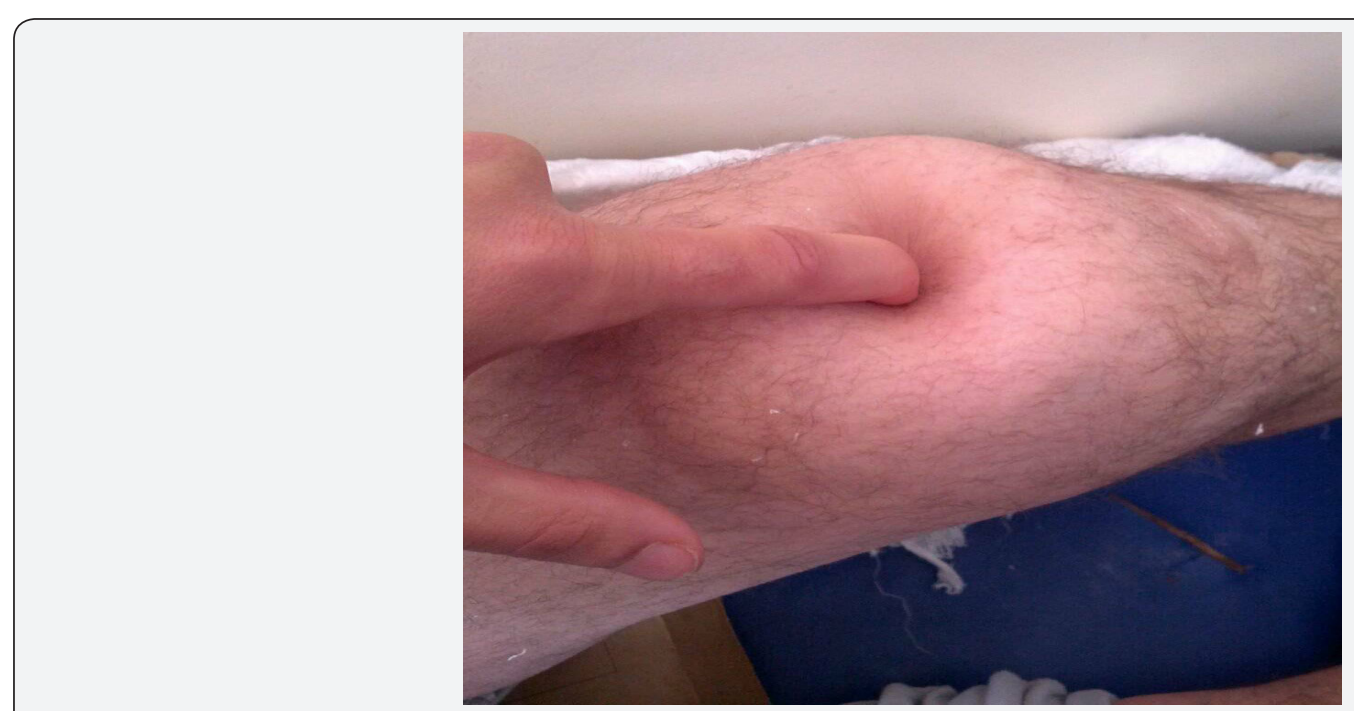

Figure 1: High riding patella with palpable defect.

Patient, 23-year-old amateur boxer, was admitted to Accidents and Emergency department for functional impairment of the right lower limb resulting from a ski accident one (01) hour prior to his admission. Patient recounted direct right knee impact on fall with blocked foot and body projecting backwards. There was no history of chronic illness, nor previous trauma or medication. Physical examination found a conscious patient in good general condition with a body mass index of $25 \mathrm{~kg} / \mathrm{m}^{2}$. Musculoskeletal examination noted a painful right knee swelling and a palpable infra patella gap (Figure 1), Patient could not maintain active right knee extension. There was no overlying wound and neurovascular exam was unremarkable. Plain knee X-ray ruled out patella fracture. MRI came back for complete rupture of the patellar tendon with a Caton-Deschamps index at 1.4 and slight knee hemarthrosis. Cruciate ligaments were intact and so were the menisci with no bony abnormalities (Figure 2). 


\section{Orthopedics and Rheumatology Open Access Journal (OROAJ)}

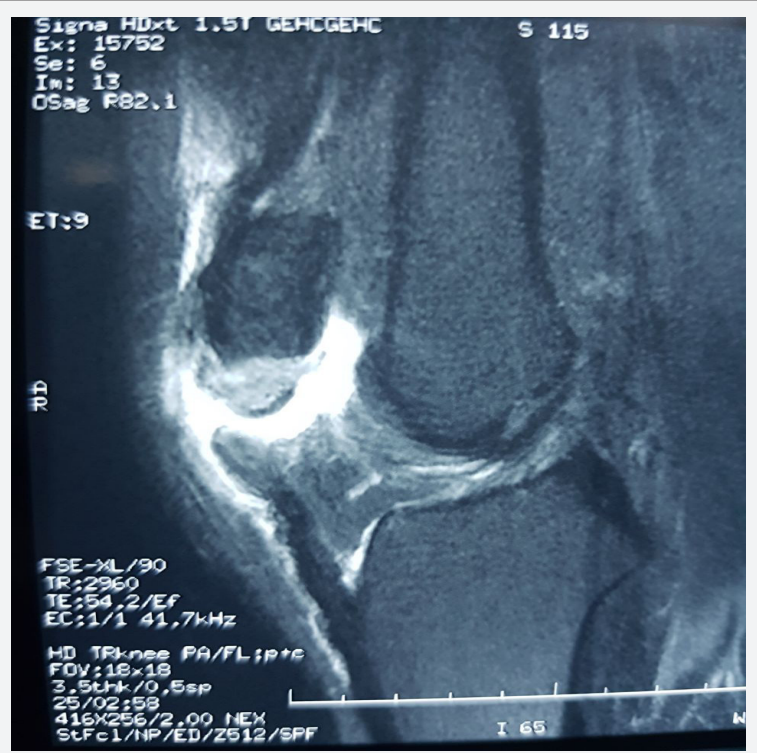

Figure 2: MRI showing complete patella tendon rupture.

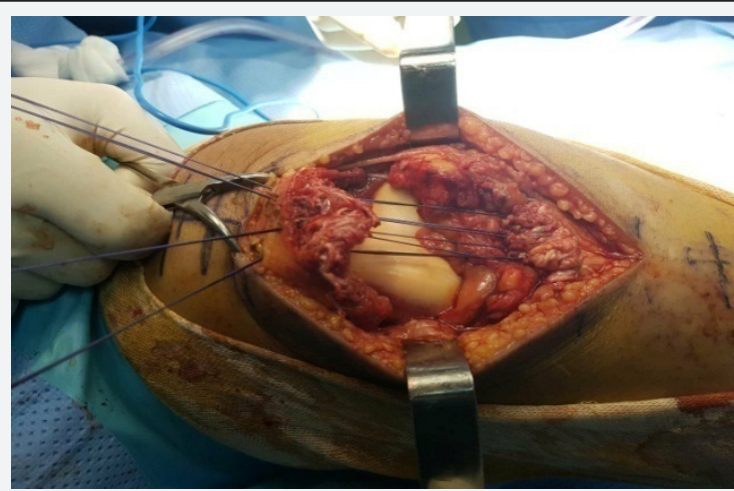

Figure 3: Trans osseous sutures passed into channels.

Patient was prepared for surgery after written informed consent was obtained. Patient underwent repair under spinal anesthesia, supine with an upper thigh tourniquet to enhance exposure. A midline longitudinal approach in line with patella tendon was employed. After careful dissection a complete rupture was observed close to the lower border of the patella which was subsequently debrided. Transosseous repair was carried out using absorbable Vicryl sutures through 4 tunnels in the inferior pole of the patella (Figure 3).

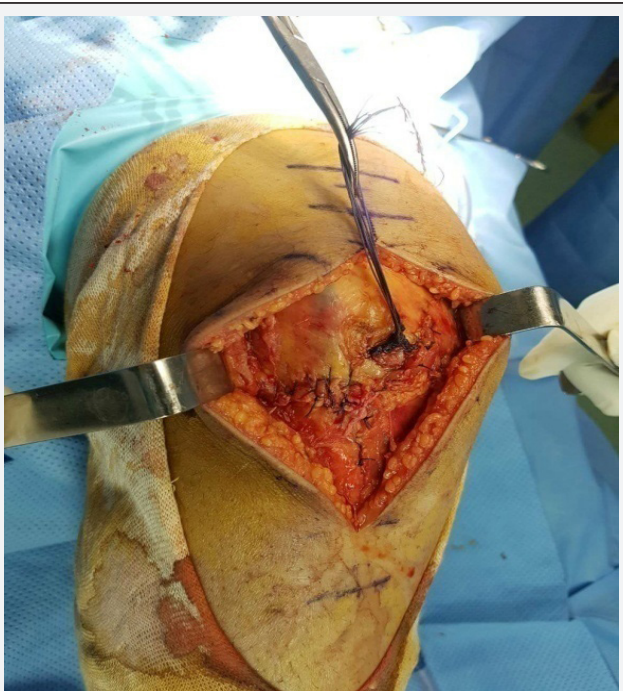

Figure 4: Peroperative image showing final construct with no gapping in repair. 


\section{Orthopedics and Rheumatology Open Access Journal (OROAJ)}

The strength of construct was tested up to $90^{\circ}$ knee flexion (Figure 4) and sutures protected with cerclage wire through the tibial tuberosity. Wound was closed on a suction drain. Postoperative x-ray done on $30^{\circ}$ flexion came back for an improved Caton-Deschamps index at 1 (Figure 5). A temporary knee brace was worn postoperatively for up to three (03) weeks. Brace ambulation with partial weight bearing was encouraged in the first three weeks. Active knee rehabilitation was intensified at 6 weeks post operatively with quadriceps and hamstring strengthening exercises. Pain relief was the main short-term goal and brace free ambulation was encouraged there onwards. After six (06) months patient had no extension lag with knee flexion at $120^{\circ}$ and a quadriceps tone $4 / 5$. No hardware complications have been reported 2 years after repair.

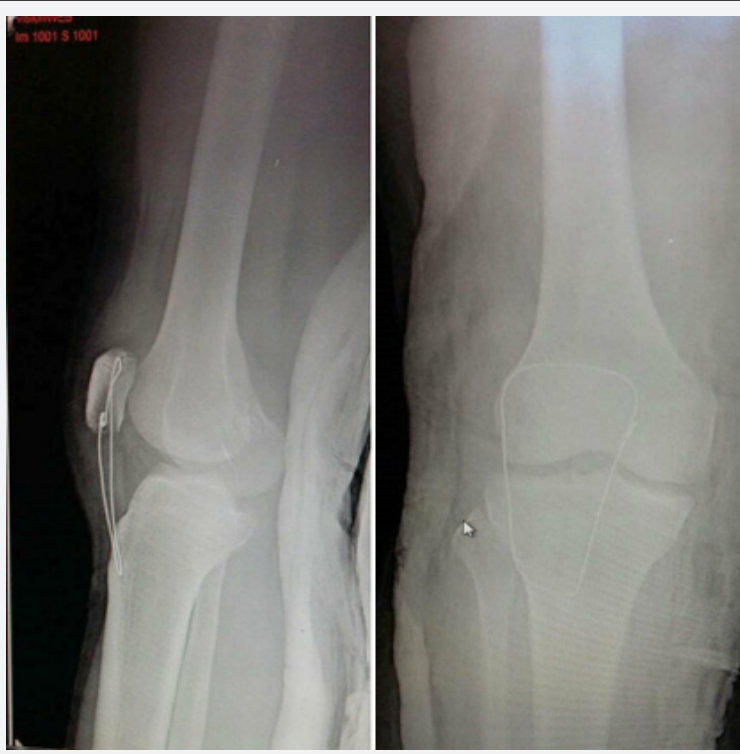

Figure 5: post-operative x-ray showing improved Caton-deschamps index at 1.

\section{Discussion}

Acute patellar tendon ruptures represents the least frequent of adult native extensor mechanism ruptures. Patient is usually unable to actively extend the knee or maintain knee extension after indirect trauma. Rupture of the extensor mechanisms below the patella leads to its ascension as a result of traction forces exerted by quadriceps. Physical examination could reveal patella gapping or knee hemarthrosis. Most ruptures occur at the lower border of the patella, but can also be midsubstance, or more rarely closer to its insertion on the tibial tuberosity.

Plain x-ray could reveal a high riding patella (patella alta). Lateral view could show a "sunrise "sign with the patella projection overlapping the femoral condyles rather than the usual skyline projection. Numerous radiological indices have been described to evaluate patella height [3]. Although it is sometimes necessary to consider such values in the light of previous trauma especially in comparison with the unaffected limb. These include the InsallSalvati ratio [4], the Blackburne-Peel index, and Caton-Deschamps index amongst others. However, the authors prefer the CatonDeschamps index as it can be measured on lateral views with knee flexion between 10 and $80^{\circ}$ unlike the Insall-Salvati ratio which can only be measured on lateral radiographs on $30^{\circ}$ knee flexion. These indexes are not only useful for preoperative diagnosis but also allow the monitoring of operated extensor mechanisms.

Similar to quadriceps tendon, ultrasonography and MRI are very useful in the preoperative workup as well specifying the location of patella tendon rupture [5]. MRI remains the gold standard as it could rule out associated soft tissue damage notably anterior cruciate ligament injury or meniscal lesions that usually accompany high-energy trauma.

Surgery remains the mainstay treatment and should not be delayed whenever local and general conditions permit [6]. Early repair guarantees satisfactory outcome. Several techniques have been previously described in literature according to location and timing of diagnosis. Repair using simple sutures with metal wire reinforcement frame was first described by Mc Laughlin in 1956 and still remains popular among several authors [1,7-11]. That notwithstanding many advocates the use of autograft as reinforcement technique as it allows for tendon augmentation in the presence poor quality tendon and reduces skin complications that could arise from the use of metal frames as reinforcement techniques. Hamstring graft $[6,12]$, or for a selected few [13] a semi-tendinous autograft and a central reinforcement by the overturning the graft on itself above the patella are the commonest augmentation techniques. Most authors are unanimous with regards to patella retinacula closure which we believe should be performed systematically [14-16]. Ait Si Selmi et al. [13], recommend a $30^{\circ}$ lateral view after tendon repair to adjust the patellar height with the unaffected side (index of Caton and Deschamps $=1 \pm 0.2$ ).

Traditionally, a knee cast in extension is worn post operatively for the first 6 weeks as brace ambulation and weight bearing are encouraged. Currently, popular evidence support early rehabilitation in the absence of complex knee injuries. Passive 
mobilization of the knee (with arthromotor) is advised often limited to $70^{\circ}$ flexion for the first 6 weeks following repair. Isometric quadriceps strengthening exercises are performed early with knee extended. Active knee extension is prohibited not advised within the first 6 weeks. Physical therapy is intensified afterwards with active range of motion exercises associated with complete knee flexion.

\section{Conclusion}

Acute rupture of the patellar tendon is rare. Meticulous examination should allow for early diagnosis as poorer outcomes are associated with delayed repair. The increasing number of repair techniques in literature is indicative of lack of clear guidelines regarding its operative management. The authors strongly believe that despite the type of repair use a safe construct is one that would allow early rehabilitation with less risk of failed repair.

\section{Conflicts of Interest}

The authors declare no potential conflict of interest with respect to the publication of this case report.

\section{Authors' Contribution}

All authors contributed to the writing of this article. The authors read and approved the final version of this manuscript.

\section{References}

1. Siwek CW, Rao JP (1981) Ruptures of the extensor mechanism of the knee joint. J Bone Joint Surg 63(6): 932-937.

2. Kelly DW, Carter VS, Jobe FW (1984) Patellar and quadriceps tendon ruptures: jumper's knee. Am J Sports Med 12(5): 975-980.

3. Seil R, Muller B, Georg T, Kohn D, Rupp S (2000) Reliability and interobserver variability in radiological patellar height ratios. Knee Surg Sports Traumatol Arthrosc 8(4): 231-236.
4. Insall J, Salvati E (1971) Patellar position in the normal knee joint. Radiology 101(1): 101-104.

5. Matava MJ (1996) Patellar tendon ruptures. J Am Acad Orthop Surg 4: 287-296.

6. Badelon O, Saillant G, Roy-Camille R (1985) Recent rupture of the patellar tendon. A propos of 9 cases. J Chir (Paris) 122(10): 519-522.

7. Dejong CH, Van de Luytgaarden WG, Vroemen JP (1991) Bilateral simultaneous rupture of the patellar tendon. Case report and review of the literature. Arch Orthop Trauma Surg 110: 222-226.

8. Giles SN, Morgan-Jones R, Brown MF (1999) The use of hinged Kirschner wires for fixation of patellar tendon rupture. Injury 30: 539540 .

9. Hsu KY, Hsu WW, Ho WP, Wang KC (1994) Traumatic patellar tendon ruptures-a follow-up study of primary repair and neutralization wire. Changgeng Yi Xue Za Zhi 17(1): 39-43.

10. Van Dale P, Opdecam P (1976) Repair of the patellar tendon: modified technic. Acta Orthop Belg 42(5): 454-458.

11. Van Glabbeek F, de Groof E, Boghemans I (1992) Bilateral patellar tendon rupture: case report and literature review. J Trauma 33(5): 790-792.

12. Ecker ML, Lotke PA, Glazer RM (1979) Late reconstruction of the patellar tendon. J Bone Joint Surg 61(6A): 84-86.

13. Ait Si Selmi T, Neyret P, Rongieras F, Caton J (1999) Ruptures de l'appareil extenseur du genou et fracturesde rotule. In: Encycl Med Chir, Techniques chirurgicales- Orthopédie-Traumatologie. Paris (Eds), 1: 44-730.

14. Marder RA, Timmerman LA (1999) Primary repair of patellar tendon rupture without augmentation. Am J Sports Med 27(3): 304-307.

15. Lindy PB, Boynton MD, Fadale PD (1995) Repair of patellar tendon disruptions without hardware. J OrthopTrauma 9(3): 238-243.

16. Kuechle DK, Stuart MJ (1994) Isolated rupture of the patellar tendon in athletes. Am J Sports Med 22: 692-695.

\begin{tabular}{|l|}
\hline \multicolumn{1}{|c|}{ Your next submission with Juniper Publishers } \\
will reach you the below assets \\
- Quality Editorial service \\
- Swift Peer Review \\
- Reprints availability \\
- E-prints Service \\
- Manuscript Podcast for convenient understanding \\
- Global attainment for your research \\
- Manuscript accessibility in different formats \\
( Pdf, E-pub, Full Text, Audio) \\
- Unceasing customer service \\
Track the below URL for one-step submission \\
https://juniperpublishers.com/online-submission.php \\
\hline
\end{tabular}

